\title{
Secreting gastro-enteropancreatic
} neuroendocrine tumours and biomarkers

\author{
Wieke H M Verbeek ${ }^{1, *}$, Catharina M Korse ${ }^{2, *}$ and Margot E T Tesselaar ${ }^{3, *}$ \\ Departments of ${ }^{1}$ Gastroenterology, ${ }^{2}$ Clinical Chemistry and ${ }^{3}$ Medical Oncology, The Netherlands Cancer \\ Institute - Antoni van Leeuwenhoek, Plesmanlaan 121, 1066 CX Amsterdam, The Netherlands \\ *(W H M Verbeek, C M Korse and M E T Tesselaar contributed equally to this work)
}

Correspondence should be addressed to M E T Tesselaar

Email

m.tesselaar@nki.nl

\begin{abstract}
Neuroendocrine tumours (NETs) are rare tumours with an annual incidence in the population in a range of 2-5 new cases per 100000 inhabitants. NETs are widely variable in terms of anatomical location, hormone production, clinical behaviour and syndromes they can cause. This article reviews the many localizations and clinical presentations of NETs with a main focus on clinical biomarkers and their use in medical practice.
\end{abstract}

\section{Introduction}

Neuroendocrine tumours (NETs), which originate from neuroendocrine cells, are found widely distributed throughout the body. The first description of these tumours was over 100 years ago by Lubarsch (1), who found multiple tumours in the distal ileum of two patients at autopsy. These tumours were firstly named carcinoid tumours (Karzinoide) in 1907 by Oberndorfer (2), to describe a small intestinal tumour that was morphologically distinct and less aggressive in behaviour that intestinal adenocarcinoma. Traditionally, these tumours were then described as originating from the foregut, midgut or hindgut (3). In most patients the primary tumour is found in the midgut and less frequently in the lung $(3,4)$. In 2010 the WHO released a new classification scheme for the digestive system based on histologic grade $(5,6,7)$. This classification divides NETs into well-differentiated NET, including grade 1 and 2 NET and poorly differentiated (grade 3 ) neuroendocrine carcinoma (NEC). The annual incidence of NET is estimated to be roughly $2-5$ cases per 100000 population $(4,8)$, though autopsy studies showed they can be found incidentally in up to $1 \%$ of necropsies $(9,10)$. Due to their relative indolent nature, there is often a delay in the diagnosis of NET, also caused by failure to identify symptoms or to establish the biochemical diagnosis. These tumours are a form of cancer that differs from other neoplasia in that they can synthesise and excrete various polypeptide hormones (e.g. Chromogranin A (CgA)) that cause specific clinical syndromes in 20-30 of cases, classified as 'functioning tumours'. However, most are clinically silent until late stages of the disease (11).

\section{Invited Author's profile}

Dr M E T Tesselaar is head of the Antoni Van Leeuwenhoek/UMC Utrecht Centre for Neuroendocrine Tumours, which is an ENETS centre of Excellence, one of the few dedicated centres in the Netherlands. Her fields of interest are head and neck oncology, including thyroid cancer and neuroendocrine tumours.

(c) 2016 European Society of Endocrinology Printed in Great Britain

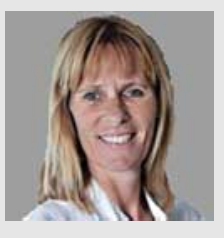

Published by Bioscientifica Ltd. 
Over the last two decades, the development of a variety of sensitive and specific plasma and/or serum assays for peptides and amines produced by NET and the development of immunohistochemistry panels has facilitated both blood and tissue diagnosis (12), followed by subsequent anatomical delineation of NET to ensure early surgical and/or pharmacological intervention to improve quality of life and survival. Management strategies for NET include surgery for cure (which is achieved rarely) or cytoreduction, radiological intervention (by radiofrequency ablation and (chemo)embolization), chemotherapy, targeted therapy and somatostatin analogues to control symptoms that result from the release of peptides and neuroamines (11). In this article we aim to give an overview on the current biomarkers secreted by NETs.

\section{Clinical presentation and localization of NET}

Neuroendocrine cells occur throughout the length of the entire gut and are the largest group of hormone-producing cells in the body $(11,13)$. At least 13 gut neuroendocrine cells exist, all of which produce various bioactive peptides or amines, including serotonin, somatostatin, histamine and gastrin. These secretory products are stored in large dense-core vesicles, and the proteins of these vesicles (e.g. CgA) are markers of neuroendocrine cells $(11,14)$. About two-thirds of NETs are of gastrointestinal or pancreatic origin (GEP-NETs), and among these the most common site of origin is the small intestine.

The clinical presentation of GEP-NET mainly depends on the site of the primary tumour, and whether the peptides secreted by the tumour cause symptoms, also called functioning or non-functioning. In most NETs histology strongly correlates with specific primary sites (Fig. 1): grade 1 NETs mostly originate in the gastrointestinal tract.

Appendiceal NETs are usually found incidentally in relatively young patients and are slow-growing tumours mostly occurring in the distal appendix where they often do not cause any symptoms. Besides location, mesoappendiceal invasion $(>3 \mathrm{~mm})$, histological atypia and the size of the tumour $(>2 \mathrm{~cm})$ are the best predictors of prognosis $(15,16)$.

Small intestinal NETs are most frequently located in the distal ileum and are often multicentric, occasionally appearing as dozens of lesions lining the small bowel (17). Patients with small intestinal NET generally present in the 6th-7th decade of life with abdominal pain or small bowel obstruction, often having years of vague abdominal complaints prior to presentation. These small intestinal
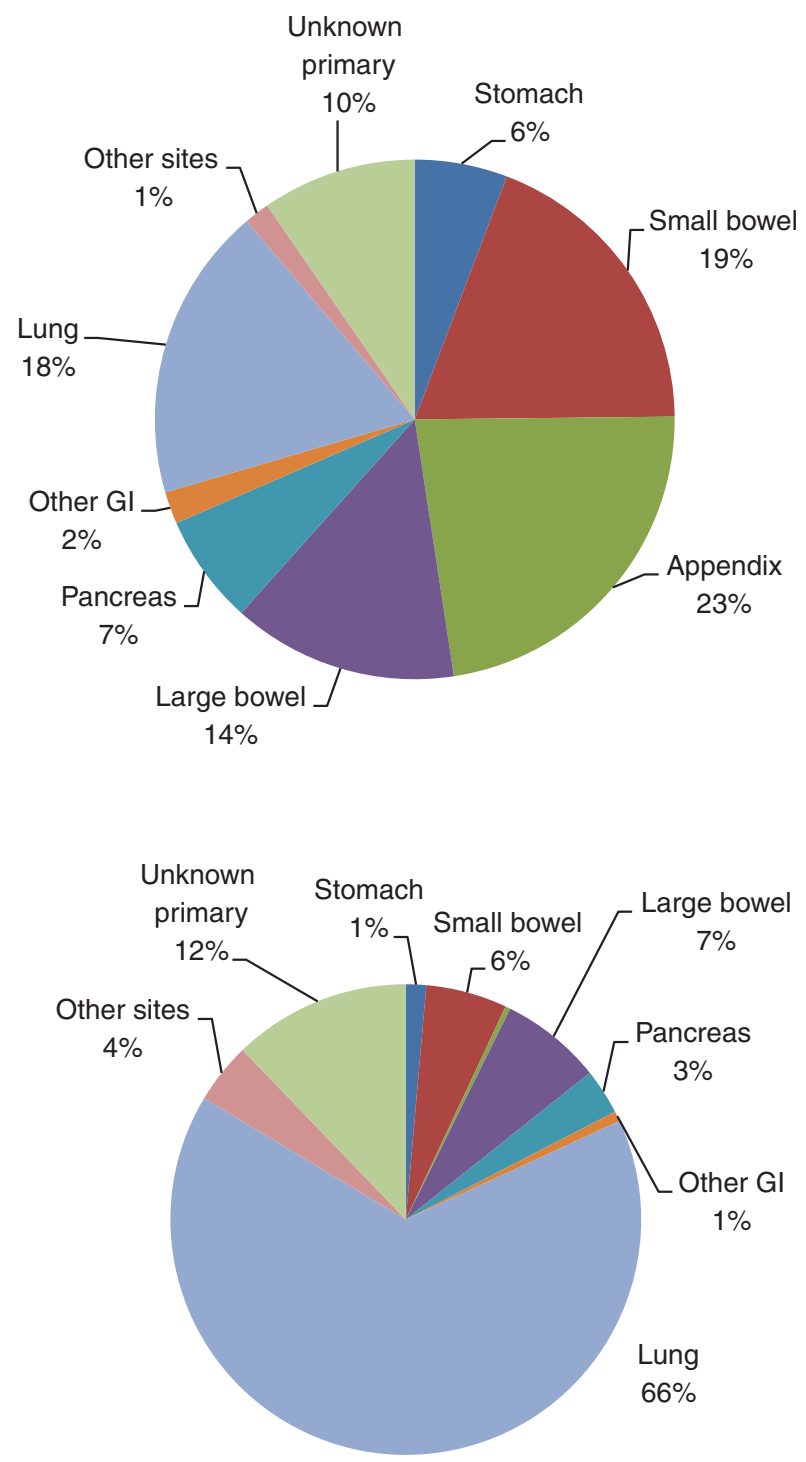

Figure 1

Anatomical distribution of grade 1 and grade 2 NET (adapted from (4)).

tumours can cause extensive mesenteric fibrosis and mesenteric ischemia $(15,16)$ Liver metastases can lead to carcinoid syndrome in $7-28 \%$ of these patients $(15,16)$, and endocardial fibrosis of the right-sided heart may occur, damaging the tricuspid and pulmonary valves, leading to impairment of cardial function, also called the carcinoid heart disease. Minority of patients (10-20\%) with carcinoid syndrome have heart disease at presentation, sometimes necessitating prosthetic valve replacement, often with a significant increase in survival (18).

Gastric NETs are typically multiple, small and localized tumours associated with hypergastrinaemia, 
either secondary to chronic atrophic gastritis (type 1) or as part of Zollinger-Ellison syndrome (ZES) (type 2 in case of MEN-1). They have low malignant potential and metastasize in $<3-5 \%$ (11). Type 3 large solitary gastric NETs, however, are not associated with hypergastrinaemia, and locoregional and hepatic metastases are very common (15). Most duodenal NETs are gastrin secreting, associated with MEN-1 in $20-30 \%$ of cases and causing ZES $(11,15)$.

NETs of the colon are mostly found in the right-sided colon, patients typically presenting with abdominal pain and weight loss. These tumours are often large, and patients commonly presenting with liver metastases $(11,15)$. Rectal NETs, however, are typically small, localized and non-functioning asymptomatic tumours, often found incidentally by endoscopy. They rarely metastasize, and local excision is the treatment of choice (15).

Pancreatic NETs are defined as epithelial tumours with a predominance of endocrine differentiation (15). A number of different clinical syndromes are recognized, reflecting the potential of pancreatic, endocrine cells to secrete both peptide and amines (depicted in detail in Table 1) (15). However, about $60-70 \%$ are non-functioning tumours and remain clinically silent until symptoms due to mass effect or metastatic disease occur in an unresectable stage (15).

In general, according to SEER data, the 5-year overall survival rate of NETs is $60-70 \%$, with the best prognosis for rectal tumours (88\%) and worst for pancreatic ones (37\%).

\section{Biomarkers}

\section{General}

Chromogranin A $\bullet$ The neuroendocrine cells in which the NET originates are unique in that each secretes a variety of biomarkers specific to different types of NET. Currently, the most frequently used biomarker for the diagnosis and follow-up of GEP-NETs is $\operatorname{CgA}(19,20,21)$. $\mathrm{CgA}$ is an acidic glycoprotein that is exclusively expressed in the secretory dense core granules of most normal en neoplastic neuroendocrine cells and upon stimulation is co-released with peptide hormones and neuropeptides $(12,22,23)$. The CgA molecule can exist in different molecular forms, depending on the type of NE cells and its concerning tumour (24). Therefore, the CgA result, measured in serum or plasma, is dependent of the

Table 1 Anatomical, clinical and biochemical features of hormonally active GEP-, bronchial- and thymic-NETs (adapted from $(15,45,46))$.

Site of the NET
Foregut
Bronchi, thymus, stomach,
1st part of duodenum,
pancreas (below)
Midgut
Second part duodenum,
jejunum, ileum, right colon
Hindgut
Transverse colon to rectum
Pancreatic
Insulinoma
Gastrinoma
Vipoma
Glucagonoma
Other rare functioning
tumours

Diagnostic serum biomarkers
5-HTP, histamine, ACTH, CRH,
CH gastrin
5-HT, tachykinins,
prostaglandins,
bradykinins and others
Peptide YY glicentin, 5-HTP, neurotensin, local production SS, other hormones

Insulin, proinsulin

Gastrin

VIP

Glucagon

SS, GRF, PTHrp, other hormones

\begin{tabular}{l}
\hline Clinical features \\
\hline Atypical flush, pulmonary \\
obstruction and hormone \\
syndroms (below) \\
Bowel obstruction, typical \\
pink/red flush, wheezing, \\
diarrhea (carcinoid \\
syndrome) \\
Local symptoms \\
Incidental finding \\
\\
Neuroglucopenia, \\
Whipple's triad \\
ZES (peptic ulcer, epigastric \\
pain, diarrhoea) \\
Watery diarrhea, \\
hypokalaemia, achlorydria \\
Cachexia, DM, necrolytic \\
migratory erythema \\
Diverse
\end{tabular}

Metastases

Liver

Lymph node

Bone

Liver (60-80\%)

Lymph Node
Bone metastases (4-40\%)

$10 \%$

$5-10 \%$

$60-90 \%$

$25 \%$

$80 \%$

$10 \%$

$80-90 \%$

$5-17 \%$

$60-80 \%$

$5-20 \%$

5-HT, 5-hydroxytryptamine; 5-HTP, 5-hydroxytryptophan; VIP, vasoactive intestinal peptide; SS, somatostatin; GRF, growth hormone releasing factor; ZES, Zollinger-Ellison syndrome; DM, diabetes mellitus. 
antibodies that are used in the immunoassay. Elevated circulating levels of CgA have been demonstrated in NET patients with both functionally and non-functionally active tumours (25), tend to correlate with tumour burden as well as recurrence and are considered a marker of bad prognosis in both ileal and pancreatic NET $(26,27,28)$. The sensitivity of the $\mathrm{CgA}$ results is around $60-80 \%$ and is dependent of primary site, grade and status of the disease (29). Moreover, significantly higher median CgA levels are found in NET patients with liver metastases (30), the highest levels in patients with functioning ileal NET and carcinoid syndrome (27). Lymph node metastases do not seem to cause a significant increase in $\operatorname{CgA}$ levels $(27,30)$.

$\mathrm{CgA}$ can be elevated in several other diseases, such as renal failure, cardiac disease and tumours other than NET, but the main cause of falsely elevated $\mathrm{CgA}$ is the use of proton pump inhibitors (PPIs) (12).

In the past, the serotonin-producing NETs were mainly diagnosed and their treatments were evaluated by measuring either serotonin or its breakdown product, 5-hydroxyindoleacetic acid (5-HIAA), in platelet-rich plasma. Stronger correlations of CgA compared to 5-HIAA with physical functioning and well-being, as well as the prognostic value of $\mathrm{CgA}$ for survival, make $\mathrm{CgA}$ the recommended marker in the management and monitoring response to various treatment strategies of patients with metastatic NETs (28). Unfortunately, however, CgA also has its limitations, as various assays are available and an international standardization is lacking. In addition, elevated CgA levels may be caused by, for example, renal or liver failure and the use of PPIs $(31,32)$. An overview of all factors increasing CgA levels, possibly contributing to false-positive test results, is shown in Table 2.

Neuron-specific enolase $\downarrow$ Neuron-specific enolase (NSE) is present in neurons and neuroendocrine cells and can be raised in tumours originating from them, especially with a high tumour burden, poor histological differentiation or a high rate of cell death. NSE is located in the cytoplasm and, unlike $\mathrm{CgA}$, is not secreted. Its diagnostic sensitivity in GEP-NETs is low (32-47\%) and is mainly the marker of choice for poorly differentiated NEC (33, 34, 35). Erythrocytes contain a large amount of NSE and can cause falsely elevated NSE levels.

Progastrin-releasing peptide and MonoTotal $\bullet$ Progastrinreleasing peptide (proGRP) is an established promising tumour marker in small-cell lung cancer $(36,37)$. In the first cross-sectional marker study in which the possible role of proGRP was evaluated in addition to the established makers CgA and NSE in the diagnosis and prognosis of 573 patients with NET and NEC as well as 282 healthy controls, pro-GRP appeared to be the most sensitive marker for small-cell NEC, especially when located in the lung. MonoTotal, an immunoassay that measured the epitopes on cytokeratin fragments 8,18 and 19 (CKfr), was also an important prognostic marker for survival in all patients with a NET. Within all histological groups, both the well-differentiated NET as well as the large- and small-cell NEC, a combination of tumour markers is more informative than each marker alone. In well-differentiated NET and large-cell NEC, CgA and CKfr was recommended, whilst in patients with small-cell NEC, proGRP and CKfr were preferred (29).

$\mathrm{N}$-terminal pro-brain natriuretic peptide $\boldsymbol{A}$ A biomarker which is useful in the early diagnosis of carcinoid heart disease is $\mathrm{N}$-terminal pro-brain natriuretic peptide (NT-proBNP), which is already widely used as a marker for left ventricular dysfunction. The overproduction of serotonin and tachykinines can affect the cardiac valves, especially the tricuspid valve, and subsequently cause the carcinoid heart disease. NET patients with elevated NT-proBNP in addition to elevated CgA levels showed

Table 2 Factors increasing CgA levels, without the presence of a (GEP-)NET (adapted from (12) and Nolting et al. (30)).

\begin{tabular}{l} 
Renal disease \\
\hline Gastrointestinal disorders \\
Non GI-cancers \\
Cardiovascular disease \\
Inflammatory disorders \\
Drugs \\
Endocrine disease \\
Others
\end{tabular}

Renal insufficiency

Chronic atrophic gastritis, pancreatitis, inflammatory bowel disease, irritable bowel syndrome, liver cirrhosis, chronic hepatitis, colon cancer, pancreatic adenocarcinoma, HCC Small-cell lung cancer, prostate cancer, breast cancer, ovary cancer, neuroblastoma Arterial hypertension, acute coronary syndrome, cardiac insufficiency, giant-cell arthritis Systemic rheumatoid arthritis, systemic inflammatory response syndrome, chronic bronchitis, airway obstruction in smokers

PPI, H2RA

Pheochromocytoma, hyperparathyroidism, pituitary tumours, medullary thyroid carcinoma, hyperthyroidism

Food intake and sports shortly before CgA measurement 
a worse overall survival than patients with elevated CgA alone (38).

NET transcripts - Modlin et al. $(39,40)$ have developed a PCR-based tool to quantitate (score) the circulating GEP-NET molecular signature ('liquid' biopsy) with high sensitivity and specificity. This test is based on 51 genes and identifies GEP-NETs. Since the blood PCR signature comprises 51 NET-based transcripts that cover a wide biological spectrum, it is also more effective than a single peptide-based ELISA that identifies a secretory peptide unrelated to tumour cell proliferation and not produced by $25 \%$ of NETs. Their observations indicate the score is elevated before tumour recurrence is detected by RECIST criteria. This signature can identify all types of GEP-NETs including small, non-metastatic tumours, is significantly reduced after tumour debulking and is absent following surgical 'cure'.

The performance metrics of this test outperformed any other biomarker information currently available for management and assessment of GEP-NETs, in particular $\mathrm{CgA}$; this still, however has to be confirmed by future prospective studies.

\section{Specific biomarkers}

Pancreatic polypeptide - For pancreatic NETs, pancreatic polypeptide may be useful for the early detection of NETs of pancreatic origin in the context of MEN-1, although this is controversial because of its low sensitivity (41). In the absence of a clinical syndrome, serum tests for an extensive set of hormones are not indicated in nonfunctioning pNETs.

Serotonin - Serotonin or 5-hydroxytryptamine (5-HT) is enzymatically transformed from the essential amino acid tryptophan following hydroxylation and decarboxylation. Serotonin was discovered and isolated from serum and determined to originate from the enterochromaffin cells found throughout the gastrointestinal and bronchopulmonary system. High concentrations of 5-HT are found in blood platelets and enterochromaffin cells of the gut. With regard to intestinal NETs, endocrine tumours of the jejunum and ileum produce serotonin, but because of the hepatic first-pass effect, this secretion only gives rise to carcinoid syndrome in patients who have developed liver metastases. Quantification of the urinary excretion of the principal metabolite of serotonin, 5 -HIAA, is 73\% sensitive and $100 \%$ specific for detecting the presence of advanced functional NET of the small intestine (42).
Insulin, gastrin, glucagon and others $>$ Functioning pancreatic tumours can be tested for specific biomarkers such as vasoactive intestinal peptide (VIP), glucagon, somatostatin, growth hormone-releasing hormone (GHRH) or ACTH, as indicated only by the patient's clinical features. For the diagnosis of an insulinoma, insulin levels are used in combination with other criteria, which include: blood glucose levels $(<2.2 \mathrm{mmol} / \mathrm{l})$, concomitant insulin levels $(>6 \mu \mathrm{U} / \mathrm{l})$, C-peptide levels ( $>200 \mathrm{pmol} / \mathrm{l})$, proinsulin levels ( $>5 \mathrm{pmol} / \mathrm{l}), \beta$-hydroxybutyrate levels $(<2.7 \mathrm{mmol} / \mathrm{l})$ and absence of sulfonylurea in plasma and urine (43). Further controlled testing includes the 72-h fast, which is the gold standard for establishing the diagnosis of insulinoma (although some studies report a 48-h fast may be adequate) (43). The diagnosis of gastrinoma is based on the existence of hypergastrinaemia $(>100 \mathrm{pg} / \mathrm{ml})$ in the presence of fasting hypersecretion of gastric acid. Whenever possible, PPIs should be discontinued for at least a week and H2-blockers for 3 days before this test is performed. However, discontinuation of PPIs in suspected gastrinoma patients should be done with extreme caution because of the danger of gastro-intestinal bleeding or perforation. If fasting serum gastrin levels are greater than tenfold elevated and gastric $\mathrm{pH}<2$, the diagnosis of ZES can be made, because the possibility of retained gastric antrum can usually be eliminated by history (44). A gastrin value of over $1000 \mathrm{pg} / \mathrm{ml}$ is highly suggestive of gastrinoma. When the fasting serum gastrin levels are between 200 and $1000 \mathrm{pg} / \mathrm{ml}$, the gold standard for the diagnosis of gastrinoma is the secretin test. This hormone, when given intravenously, provokes an increase in serum gastrin and secondarily in gastric acid secretion (44). Pancreatic NET can also produce other even more rarely occurring peptides (some mentioned in Table 2) such as VIP, glucagon, GH, ACTH, PTHrp, calcitonin, renin, LH, and erythropoietin (43).

\section{Summary}

NETs are rare tumours, with an annual incidence estimated as 2-5 cases per 100000 population. They are able to produce non-specific and specific biomarkers. Presently the most frequently used biomarker in GEPNETs is $\operatorname{CgA}$, although it is a non-specific biomarker and has its limitations. More specific markers can be used in functioning NET. The use of NEN transcripts is promising, but its application of this PCR-based blood test in patients with a NET is still in research. 


\section{Declaration of interest}

The authors declare that there is no conflict of interest that could be perceived as prejudicing the impartiality of the review.

\section{Funding}

This review did not receive any specific grant from any funding agency in the public, commercial or not-for-profit sector.

\section{References}

1 Lubarsch O. Uber den pimaeren krebs des ileum nebst Bemerkungen ueber das gleichzeitige Vorkommen von krebs und tuberculos. Virchows Archiv 1888111 46. (doi:10.1007/BF01966242)

2 Oberndorfer S. Karzinoide Tumoren des Dünndarms. Frankfurter Zeitschrift für Pathologie 19071 426-432.

3 Williams ED \& Sandler M. The classification of carcinoid tum ours. Lancet 19631 238-239. (doi:10.1016/S0140-6736(63)90951-6)

4 Korse CM, Taal BG, van Velthuysen ML \& Visser O. Incidence and survival of neuroendocrine tumours in the Netherlands according to histological grade: experience of two decades of cancer registry. European Journal of Cancer 201349 1975-1983. (doi:10.1016/j.ejca. 2012.12.022)

5 Bosman FT, Carneiro F, Hruban RH \& Theise ND. WHO Classification of the Tumours of the Digestive System. Lyon, France: IARC Press, 2010.

6 Klimstra DS, Modlin IR, Coppola D, Lloyd RV \& Suster S. The pathologic classification of neuroendocrine tumors: a review of nomenclature, grading, and staging systems. Pancreas 201039 707-712. (doi:10.1097/ MPA.0b013e3181ec124e)

7 Travis WD, Rush W, Flieder DB, Falk R, Fleming MV, Gal AA \& Koss MN. Survival analysis of 200 pulmonary neuroendocrine tumors with clarification of criteria for atypical carcinoid and its separation from typical carcinoid. American Journal of Surgical Pathology 199822 934-944. (doi:10.1097/00000478-199808000-00003)

8 Yao JC, Hassan M, Phan A, Dagohoy C, Leary C, Mares JE, Abdalla EK, Fleming JB, Vauthey JN, Rashid A et al. One hundred years after "carcinoid": epidemiology of and prognostic factors for neuroendocrine tumors in 35,825 cases in the United States. Journal of Clinical Oncology 200826 3063-3072. (doi:10.1200/JCO.2007.15.4377)

9 Berge T \& Linell F. Carcinoid tumours. Frequency in a defined population during a 12-year period. Acta Pathologica et Microbiologica Scandinavica. Section A, Pathology 197684 322-330.

10 Hodgson HJ. Carcinoid tumours and the carcinoid syndrome. In Gastroenterology: Clinical Science and Practic, pp 643-658. London: WB Saunders, 1992.

11 Modlin IM, Oberg K, Chung DC, Jensen RT, De Herder WW, Thakker RV, Caplin M, Delle Fave G, Kaltsas GA, Krenning EP et al. Gastroenteropancreatic neuroendocrine tumours. Lancet. Oncology 20089 61-72. (doi:10.1016/S1470-2045(07)70410-2)

12 Modlin IM, Gustafsson BI, Moss SF, Pavel M, Tsolakis AV \& Kidd M. Chromogranin A - biological function and clinical utility in neuro endocrine tumor disease. Annals of Surgical Oncology 201017 2427-2443. (doi:10.1245/s10434-010-1006-3)

13 Rehfeld JF. The new biology of gastrointestinal hormones. Physiological Reviews 199878 1087-1108.

14 Wiedenmann B, John M, Ahnert-Hilger G \& Riecken EO. Molecular and cell biological aspects of neuroendocrine tumors of the gastroenteropancreatic system. Journal of Molecular Medicine 199876 637-647. (doi:10.1007/s001090050261)

15 Kaltsas GA, Besser GM \& Grossman AB. The diagnosis and medical management of advanced neuroendocrine tumors. Endocrine Reviews 200425 458-511. (doi:10.1210/er.2003-0014)
16 Kulke MH \& Mayer RJ. Carcinoid tumors. New England Journal of Medicine 1999340 858-868. (doi:10.1056/NEJM199903183401107)

17 Moertel CG, Sauer WG, Dockerty MB \& Baggenstoss AH. Life history of the carcinoid tumor of the small intestine. Cancer $196114901-912$. (doi:10.1002/1097-0142(196109/10)14:5 < 901::AID-CNCR28 20140502>3.0.CO;2-Q)

18 Moller JE, Pellikka PA, Bernheim AM, Schaff HV, Rubin J \& Connolly HM. Prognosis of carcinoid heart disease: analysis of 200 cases over two decades. Circulation 2005112 3320-3327. (doi:10.1161/ CIRCULATIONAHA.105.553750)

19 Kanakis G \& Kaltsas G. Biochemical markers for gastroenteropancreatic neuroendocrine tumours (GEP-NETs). Best Practice \& Research. Clinical Gastroenterology 201226 791-802. (doi:10.1016/j.bpg.2012.12.006)

20 Arnold R, Chen YJ, Costa F, Falconi M, Gross D, Grossman AB, Hyrdel R, Kos-Kudla B, Salazar R, Plockinger U et al. ENETS Consensus Guidelines for the Standards of Care in Neuroendocrine Tumors: follow-up and documentation. Neuroendocrinology 200990 227-233. (doi:10.1159/ $000225952)$

21 Oberg K. Circulating biomarkers in gastroenteropancreatic neuroendocrine tumours. Endocrine-Related Cancer 201118 (Suppl 1) S17-S25. (doi:10.1530/ERC-10-0280)

22 Deftos LJ. Chromogranin A: its role in endocrine function and as an endocrine and neuroendocrine tumor marker. Endocrine Reviews 1991 12 181-187. (doi:10.1210/edrv-12-2-181)

23 Taupenot L, Harper KL \& O'Connor DT. The chromogranin-secretogranin family. New England Journal of Medicine 2003348 1134-1149. (doi:10.1056/NEJMra021405)

24 Barakat MT, Meeran K \& Bloom SR. Neuroendocrine tumours. Endocrine-Related Cancer 200411 1-18. (doi:10.1677/erc.0.0110001)

25 Nobels FR, Kwekkeboom DJ, Bouillon R \& Lamberts SW. Chromogranin A: its clinical value as marker of neuroendocrine tumours. European Journal of Clinical Investigation 199828 431-440. (doi:10.1046/ j.1365-2362.1998.00305.x)

26 Welin S, Stridsberg M, Cunningham J, Granberg D, Skogseid B, Oberg K, Eriksson B \& Janson ET. Elevated plasma chromogranin A is the first indication of recurrence in radically operated midgut carcinoid tumors. Neuroendocrinology 200989 302-307. (doi:10.1159/000179900)

27 Arnold R, Wilke A, Rinke A, Mayer C, Kann PH, Klose KJ, Scherag A, Hahmann M, Muller HH \& Barth P. Plasma chromogranin A as marker for survival in patients with metastatic endocrine gastroenteropancreatic tumors. Clinical Gastroenterology and Hepatology 20086 820-827. (doi:10.1016/j.cgh.2008.02.052)

28 Korse CM, Bonfrer JM, Aaronson NK, Hart AA \& Taal BG. Chromogranin $A$ as an alternative to 5-hydroxyindoleacetic acid in the evaluation of symptoms during treatment of patients with neuroendocrine tumors. Neuroendocrinology 200989 296-301. (doi:10.1159/000162876)

29 Korse CM, Taal BG, Vincent A, van Velthuysen ML, Baas P, BuningKager JC, Linders TC \& Bonfrer JM. Choice of tumour markers in patients with neuroendocrine tumours is dependent on the histological grade. A marker study of Chromogranin A, Neuron specific enolase, Progastrin-releasing peptide and cytokeratin fragments. European Journal of Cancer 201248 662-671. (doi:10.1016/j.ejca.2011.08.012)

30 Nolting S, Kuttner A, Lauseker M, Vogeser M, Haug A, Herrmann KA, Hoffmann JN, Spitzweg C, Goke B \& Auernhammer CJ. Chromogranin a as serum marker for gastroenteropancreatic neuroendocrine tumors: a single center experience and literature review. Cancer 20124 141-155. (doi:10.3390/cancers4010141)

31 Giusti M, Sidoti M, Augeri C, Rabitti C \& Minuto F. Effect of short-term treatment with low dosages of the proton-pump inhibitor omeprazole on serum chromogranin A levels in man. European Journal of Endocrinology/European Federation of Endocrine Societies 2004150 299-303. (doi:10.1530/eje.0.1500299)

32 Korse CM, Muller M \& Taal BG. Discontinuation of proton pump inhibitors during assessment of chromogranin A levels in patients with neuroendocrine tumours. British Journal of Cancer 2011105 1173-1175. (doi:10.1038/bjc.2011.380) 
33 De Herder WW. Biochemistry of neuroendocrine tumours. Best Practice \& Research. Clinical Endocrinology \& Metabolism 200721 33-41. (doi:10.1016/j.beem.2006.12.002)

34 Eriksson B, Oberg K \& Stridsberg M. Tumor markers in neuroendocrine tumors. Digestion 200062 (Suppl 1) 33-38. (doi:10.1159/ 000051853)

35 Nobels FR, Kwekkeboom DJ, Coopmans W, Schoenmakers CH, Lindemans J, De Herder WW, Krenning EP, Bouillon R \& Lamberts SW. Chromogranin A as serum marker for neuroendocrine neoplasia: comparison with neuron-specific enolase and the alpha-subunit of glycoprotein hormones. Journal of Clinical Endocrinology and Metabolism 199782 2622-2628.

36 Barak V, Goike H, Panaretakis KW \& Einarsson R. Clinical utility of cytokeratins as tumor markers. Clinical Biochemistry 200437 529-540. (doi:10.1016/j.clinbiochem.2004.05.009)

37 Molina R, Filella X \& Augé JM. ProGRP: a new biomarker for small cell lung cancer. Clinical Biochemistry 200437 505-511.

38 Korse CM, Taal BG, de Groot CA, Bakker RH \& Bonfrer JM. Chromogranin-A and N-terminal pro-brain natriuretic peptide: an excellent pair of biomarkers for diagnostics in patients with neuroendocrine tumor. Journal of Clinical Oncology 200927 4293-4299. (doi:10.1200/JCO.2008.18.7047)

39 Modlin IM, Drozdov I \& Kidd M. The identification of gut neuroendocrine tumor disease by multiple synchronous transcript analysis in blood. PLoS ONE 20138 e63364. (doi:10.1371/journal.pone.0063364)

40 Modlin IM, Aslanian H, Bodei L, Drozdov I \& Kidd M. A PCR blood test outperforms chromogranin A in carcinoid detection and is unaffected by proton pump inhibitors. Endocrine Connections 20143 215-223. (doi:10.1530/EC-14-0100)

41 de Laat JM, Pieterman CR, Weijmans M, Hermus AR, Dekkers OM, de Herder WW, van der Horst-Schrivers AN, Drent ML, Bisschop PH Havekes B et al. Low accuracy of tumor markers for diagnosing pancreatic neuroendocrine tumors in multiple endocrine neoplasia type 1 patients. Journal of Clinical Endocrinology and Metabolism 2013 98 4143-4151. (doi:10.1210/jc.2013-1800)

42 Ardill JE \& Erikkson B. The importance of the measurement of circulating markers in patients with neuroendocrine tumours of the pancreas and gut. Endocrine-Related Cancer 200310 459-462. (doi:10.1677/erc.0.0100459)

43 Jensen RT, Cadiot G, Brandi ML, de Herder WW, Kaltsas G, Komminoth P, Scoazec JY, Salazar R, Sauvanet A, Kianmanesh R et al. ENETS Consensus Guidelines for the management of patients with digestive neuroendocrine neoplasms: functional pancreatic endocrine tumor syndromes. Neuroendocrinology 201295 98-119. (doi:10.1159/ 000335591)

44 O'Toole D, Grossman A, Gross D, Delle Fave G, Barkmanova J, O'Connor J, Pape UF \& Plockinger U. ENETS Consensus Guidelines for the Standards of Care in Neuroendocrine Tumors: biochemical markers. Neuroendocrinology 200990 194-202. (doi:10.1159/ 000225948)

45 Mignon M. Natural history of neuroendocrine enteropancreatic tumors. Digestion 200062 (Suppl 1) 51-58. (doi:10.1159/ 000051856)

46 Caplin M \& Yao J. Handbook of Gastroenteropancreatic and Thoracic Neuroendocrine Tumours. Bristol: Bioscientifica, 2011.

Received 18 November 2014

Revised version received 24 June 2015

Accepted 8 July 2015 